\title{
The Effect of Volatilisation of Refractory Metal Oxides on the Cyclic Oxidation of Ni-base Superalloys
}

\author{
G. Brewster ${ }^{1}$, I.M. Edmonds ${ }^{1}$, S. Gray ${ }^{2}$ \\ ${ }^{1}$ Rolls-Royce plc, PO BOX 31, Derby, DE24 8BJ, UK \\ ${ }^{2}$ Cranfield University, Cranfield, Bedford, MK43 OAL, UK
}

\begin{abstract}
The role of refractory metals on the bare oxidation behaviour of a range of compositionally complex single crystal Ni-base superalloys has been investigated using a range of techniques. It has been shown that this series of $4^{\text {th }}$ generation alloys were borderline alumina formers at $1100^{\circ} \mathrm{C}$, and their cyclic oxidation performance was detrimentally affected by increased levels of Mo and Co. In addition, there was strong evidence that $\mathrm{Re}, \mathrm{Ru}$ and Mo were lost through the process of cyclic oxidation, which supports the hypothesis that these elemental additions were lost through volatilisation/sublimation, contributing to their poor cyclic oxidation performance.
\end{abstract}

Keywords: Ni-base Superalloy, Cyclic Oxidation, Volatilisation

\section{$\underline{\text { Introduction }}$}

The challenging environment found for components in the turbine section of gas turbine engines has led to the development of compositionally complex single crystal Ni-base superalloys. In order to achieve improved high temperature creep and fatigue strengths, the trend has been for refractory elements, principally Mo, W, Ta, Re and Ru, to add at the expense of elements that are known to benefit environmental resistance, namely $\mathrm{Al}$ and $\mathrm{Cr}$ [1]. However, the influence of these refractory elements on the overall oxidation resistance, and the trades between them, are not full understood. 
A number of these refractory metals have the potential to form volatile oxides within the temperature range of operation, the most relevant of which are $\mathrm{Re}_{2} \mathrm{O}_{7}, \mathrm{RuO}_{4}, \mathrm{MoO}_{3}, \mathrm{WO}_{3}[2-$ 4]. These volatile oxides are typically found towards the top of the Ellingham Diagram, indicating that they are not particularly thermodynamically stable. For this reason it is not anticipated they should be formed once a continuous oxide develops, provided that oxide is dense in nature, but may play a role during the competitive transient oxidation stage in affecting the propensity to form a protective oxide or its quality. For bare materials in operating environments where the spallation may routinely occur due to environmental and mechanical reasons, the proportion of operation spent in this transient oxidation stage can be significant.

Numerous references exist in the literature which refer to the disruptive effect of volatilising gaseous oxides on the adherence of alumina scales, although few provide direct evidence of the occurrence of volatilisation. Kawagishi et al. [5, 6] and Feng et al. [7] refer to the volatilisation of $\mathrm{Ru}$ oxide, whilst Bellina et al. detail the formation of volatile $\mathrm{Ru}$ oxide vapour disrupting the scale formed on RuAl modified bondcoats $[8,9]$. Similarly in a series of papers, Moniruzzaman et al. [10,11, 12] refer to the formation of porous oxides because of the high vapour pressure of dirhenium heptoxide, $\operatorname{Re}_{2} \mathrm{O}_{7}$. Younes et al. also allude to the formation of volatile Re oxides by virtue of their absence from the spinel phases formed, which contain most of the other refractory elements to some degree [13]. Mo is another refractory metal which is known to form volatile oxides at elevated temperatures. Whilst the boiling point of $\mathrm{MoO}_{3}$ is relatively high $\left(1155^{\circ} \mathrm{C}\right)$ it has been shown to sublime at temperatures as low as $450^{\circ} \mathrm{C}$ [14]. Mo has been reported to have a negative impact on the cyclic oxidation resistance of Ni-base superalloys by a number of authors $[15,16]$, and $\mathrm{MoO}_{3}$ itself has been observed as a condensed phase after oxidation [17].

This paper further investigates refractory oxide volatilisation using a range of approaches to further elucidate this phenomenon.

\section{Experimental Procedure}

Eight single crystal Ni-base superalloys were designed, devised and evaluated using a design of experiments approach to isolate the effects of four of the elements, namely Co, Mo, W and 


\begin{tabular}{|l|l|l|l|l|l|l|l|l|l|l|l|}
\hline Alloy & $\mathbf{N i}$ & $\mathbf{A l}$ & $\mathbf{C o}$ & $\mathbf{C r}$ & $\mathbf{M o}$ & $\mathbf{T i}$ & $\mathbf{T a}$ & $\mathbf{W}$ & $\mathbf{R e}$ & $\mathbf{R u}$ & $\mathbf{H f}$ \\
\hline LDSX-1 & Bal. & 6.0 & 3.0 & 3.0 & 2.5 & 0.25 & 6.5 & 2.9 & 6.2 & 3.5 & 0.1 \\
\hline LDSX-2 & Bal. & 6.0 & 8.0 & 3.0 & 5.0 & 0.25 & 6.5 & 2.9 & 6.2 & 3.5 & 0.1 \\
\hline LDSX-3 & Bal. & 6.0 & 3.0 & 3.0 & 5.0 & 0.25 & 6.5 & 4.8 & 6.2 & 3.5 & 0.1 \\
\hline LDSX-4 & Bal. & 6.0 & 8.0 & 3.0 & 2.5 & 0.25 & 6.5 & 4.8 & 6.2 & 3.5 & 0.1 \\
\hline LDSX-5 & Bal. & 6.0 & 8.0 & 3.0 & 2.5 & 0.25 & 6.5 & 2.9 & 6.2 & 5.0 & 0.1 \\
\hline LDSX-6 & Bal. & 6.0 & 3.0 & 3.0 & 2.5 & 0.25 & 6.5 & 4.8 & 6.2 & 5.0 & 0.1 \\
\hline LDSX-7 & Bal. & 6.0 & 3.0 & 3.0 & 5.0 & 0.25 & 6.5 & 2.9 & 6.2 & 5.0 & 0.1 \\
\hline LDSX-8 & Bal. & 6.0 & 8.0 & 3.0 & 5.0 & 0.25 & 6.5 & 4.8 & 6.2 & 5.0 & 0.1 \\
\hline
\end{tabular}

Table 1 Nominal compositions of the experimental LDSX Ni-base superalloy series (weight $\%)[18]$

\section{Oxidation Testing}

The bare cyclic oxidation resistance of the bare (uncoated) alloy series was tested at $1100^{\circ} \mathrm{C}$. Each cycle comprised a $1 \mathrm{~h}$ soak at peak temperature $\left(>0.97 \mathrm{~T}_{\text {dwell }}\right)$ followed by a $10 \mathrm{~min}$ blast with compressed air in a cooling station. Samples of each alloy, $8 \mathrm{~mm}$ diameter and 50 $\mathrm{mm}$ long in dimension, were exposed to a maximum of 200 cycles. The initial weight and dimensions of the test pieces were measured using a calibrated balance and micrometer, while the mass change was monitored with a calibrated balance throughout the test at 5 cycle intervals. Upon completion, the mass change was converted to specific mass change by normalising the data against the specimen surface area. These specimens were analysed using scanning electron microscopy (SEM) and X-ray diffraction (XRD).

Thermo gravimetric analysis (TGA) was performed on specimens of both LDSX-1 and LDSX-2 at $1100^{\circ} \mathrm{C}$. TGA was performed on a CI Electronics MK2-M5 thermo gravimetric mass balance, with a sensitivity of $0.1 \mu \mathrm{g}$. Testing was conducted in standing laboratory air, using an open system for $24 \mathrm{hs}$. 
One additional LDSX-8 sample was cyclically oxidised under the same conditions as above, however the test was continued until the metallic specimen was entirely consumed. The spall was then collected and analysed using both XRD, then X-ray fluorescence (XRF) and inductively coupled plasma- optical emission spectroscopy (ICP-OES) to determine the composition.

\section{$\underline{\text { Sample Analysis }}$}

A Philips XL-30 field emission gun SEM operating with an accelerating voltage of $25 \mathrm{kV}$ and working distance of $10 \mathrm{~mm}$ was used for imaging and basic compositional analysis of the oxide species.

XRD was performed on the cyclic oxidation samples of each alloy that had seen $~ 150$ cycles, and the LDSX-8 alloy that had been completely oxidised. Measurements were made on a Bruker AXS D8 Advance X-ray diffractometer with a LynxEye detector in standard $\theta / 2 \theta$ Bragg-Brentano operation. Scans were performed for $2 \theta$ range of $20-90^{\circ}$ with a step size of $0.03^{\circ}$ and a $0.5^{\circ}$ divergent slit. Specimens were rotated during the scan in order to average over the specimen area.

XRF was performed in accordance with BSEN ISO 12677:2011, scanning for the following: $\mathrm{SiO}_{2}, \mathrm{TiO}_{2}, \mathrm{Al}_{2} \mathrm{O}_{3}, \mathrm{Fe}_{2} \mathrm{O}_{3}, \mathrm{CaO}, \mathrm{MgO}, \mathrm{K}_{2} \mathrm{O}, \mathrm{Na}_{2} \mathrm{O}, \mathrm{P}_{2} \mathrm{O}_{5}, \mathrm{Cr}_{2} \mathrm{O}_{3}, \mathrm{Mn}_{3} \mathrm{O}_{4}, \mathrm{ZrO}_{2}, \mathrm{HfO}_{2}, \mathrm{PbO}$, $\mathrm{ZnO}, \mathrm{BaO}, \mathrm{SrO}, \mathrm{SnO}_{2}, \mathrm{CuO}, \mathrm{Y}_{2} \mathrm{O}_{3}, \mathrm{U}_{3} \mathrm{O}_{8}, \mathrm{ThO}_{2}, \mathrm{Bi}_{2} \mathrm{O}_{3}, \mathrm{NiO}, \mathrm{CoO}, \mathrm{Sb}_{2} \mathrm{O}_{3}, \mathrm{~V}_{2} \mathrm{O}_{5}, \mathrm{As}_{2} \mathrm{O}_{3}$, $\mathrm{CeO}_{2}, \mathrm{La}_{2} \mathrm{O}_{3}, \mathrm{Nb}_{2} \mathrm{O}_{5}, \mathrm{Ga}_{2} \mathrm{O}_{3}, \mathrm{CdO}, \mathrm{MoO}_{3}, \mathrm{Pr}_{6} \mathrm{O}_{11}, \mathrm{CS}_{2} \mathrm{O}, \mathrm{Gd}_{2} \mathrm{O}_{3}, \mathrm{Nd}_{2} \mathrm{O}_{3}, \mathrm{SM}_{2} \mathrm{O}_{3}, \mathrm{TeO}_{2}, \mathrm{SO}_{3}$, $\mathrm{Dy}_{2} \mathrm{O}_{3}, \mathrm{Er}_{2} \mathrm{O}_{3}, \mathrm{Eu}_{2} \mathrm{O}_{3}, \mathrm{GeO}_{2}, \mathrm{Ho}_{2} \mathrm{O}_{3}, \mathrm{Lu}_{2} \mathrm{O}_{3}, \mathrm{Rb}_{2} \mathrm{O}, \mathrm{Sc}_{2} \mathrm{O}_{3}, \mathrm{Ta}_{2} \mathrm{O}_{5}, \mathrm{~Tb}_{2} \mathrm{O}_{3}, \mathrm{Tl}_{2} \mathrm{O}_{3}, \mathrm{Tm}_{2} \mathrm{O}_{3}$, $\mathrm{Yb}_{2} \mathrm{O}_{3}$ and $\mathrm{F}$.

ICP-OES analysis was used to determine the Re and Ru levels, and performed with an Agilent 700 series system. This was performed by putting the sample in a crucible, igniting it to obtaining a loss / gain on ignition. Due to the low levels of spall available, and to enable measurement, the spall was mixed with silica, alumina and a flux. 


\section{$\underline{\text { Results and Discussion }}$}

\section{Cyclic Oxidation Testing}

Cyclic oxidation testing results indicated a large spread in oxidation resistance, bounded by the least highly alloyed and best performing variant, LDSX-1, and the most highly alloyed and worst performing variant, LDSX-8 (see Figure 1). Statistical analysis of the mass loss data (after 100 cycles) through the experimental design highlighted both Mo and Co to be detrimental to cyclic oxidation performance, with Mo explaining $79 \%$ of the variation in mass loss, see Figure 2. This behaviour is consistent with the other work in the literature that has also shown Mo to have a negative impact on cyclic oxidation performance $[15,16]$. Microstructural analysis showed that the surfaces of all the oxidation specimens displayed a variation in the extent of the section change around the circumference, typical of long term cyclic oxidation. Despite the different alloy compositions, the same broad oxide species and morphologies differed were observed on all of the alloys tested, although the relative proportions did differ depending on the specific sample and the location around the circumference. Typical oxide morphologies and compositional maps of the principal elements are shown in Figure 3. They consisted of an externally grown nickel oxide layer, with an internal nickel aluminium oxide layer, punctuated with a large number of small, refractory rich oxides, shown by EDS to be predominantly Ta and W rich. Between this layer and the substrate is a thin, either continuous or discontinuous, layer of aluminium oxide that grows because the oxygen activity has been lowered by this external layer. Internal to this there exist a $\gamma^{\prime}$ depleted zone due to the aluminium depletion caused by consumption of elements through oxidation. This broad microstructure is consistent with other cyclic oxidation studies of similar materials $[5,6]$.

These observations were refined by the XRD analyses, see Figure 4. Analysis of the results showed pronounced substrate $\gamma$ and $\gamma^{\prime}$ lattice reflections in many of specimens, indicating that the entire oxide layer was being sampled. All of the alloys formed the same aggregate oxide species with very prominent reflections from nickel oxide $(\mathrm{NiO})$, nickel aluminium oxide $\left(\mathrm{NiAl}_{2} \mathrm{O}_{4}\right)$ and nickel tantalum oxide $\left(\mathrm{NiTa}_{2} \mathrm{O}_{6}\right)$ species. Less prominent were the peaks from nickel tungsten oxide $\left(\mathrm{NiWO}_{4}\right)$ and nickel molybdenum oxide $\left(\mathrm{NiMoO}_{4}\right)$ and alumina $\left(\mathrm{Al}_{2} \mathrm{O}_{3}\right)$ due to the small volume fraction of the species present. 


\section{TGA Oxidation Studies}

To rationalise the negative impact of these two elements on the cyclic oxidation resistance of the LDSX alloys, LDSX-1 and LDSX-2 were tested using TGA; note LDSX-2 is a higher Mo and Co-containing variant of LDSX-1 (Table 1).

On the initial ramp up to temperature, when the samples were in the temperature range 400$500^{\circ} \mathrm{C}$, a small dip in the specific mass gain curves of both specimens was evident (see Figure 5). It was noted that this dip in the trace has corresponded to the temperature at $\mathrm{MoO}_{3}$ has been reported to sublime [14] and would be consistent with volatilisation/sublimation of one of the oxide species. This test was repeated with a 'cold finger' in an attempt to condense any gaseous oxide phases present, however nothing was detected, so the reason for this could not be uniquely identified.

As evident in Figure 5, both alloys behaved similarly over the duration of the test. Importantly, from the perspective of cyclic oxidation, after approximately a $1 \mathrm{~h}$ isothermal exposure, at which point the first cooling cycle would have taken place in the cyclic oxidation test, both alloys have past the initial transient oxidation stage and exhibit similar oxidation rates, suggesting a similar degree of protection at that point. After 24 hs both alloys exhibit parabolic growth rates close to that of $\alpha$-alumina, suggesting that is the predominant protective oxide. Subsequent microstructural examination of the test specimens showed the presence of identical multilayer oxides on both alloys comprising an internal alumina layer ( $\sim 1 \mu \mathrm{m}$ thick) surrounded by an external layer of nickel aluminium oxide $(\sim 1 \mu \mathrm{m}$ thick) with small nickel tantalum oxide particles sandwiched in between. An external layer of nickel oxide layer was observed to have formed but spalled upon cooling to room temperature. The presence of alumina beneath both the nickel oxide and nickel aluminium oxide scales indicates that these alloys are borderline external alumina formers. This explains the poor cyclic oxidation performance of these alloys as compared to an external alumina former, such as CMSX-4. Any subsequent loss of the initial oxide layer would reveal a substrate more depleted in aluminium and therefore less able to re-form a protective oxide scale. 


\section{Cyclic Oxidation to Complete Alloy Consumption}

Powder XRD was performed on the collected spall (see Figure 4), and the following principal oxides were observed: Nickel Oxide (NiO), Nickel Tungsten Oxide $\left(\mathrm{NiWO}_{4}\right)$ and Nickel Tantalum Oxide $\left(\mathrm{NiTa}_{2} \mathrm{O}_{6}\right)$. These are consistent with the oxides observed on the interrupted cyclic oxidation samples, with the notable absence of nickel molybdenum oxide $\left(\mathrm{NiMoO}_{4}\right)$ and alumina $\left(\mathrm{Al}_{2} \mathrm{O}_{3}\right)$.

The results of the XRF analysis for the oxides of the remaining species in the spall (where the composition was $\geq 0.01 \mathrm{wt} \%$ ) is provided in Table 2 as well as the conversion of this to equivalent composition of the equivalent 'unoxidised' alloy composition. In addition to this, the ICP-OES analysis revealed less than 10ppm Re and Ru present in the spall, hence these elements have been omitted from Table 2 . 


\begin{tabular}{|c|c|c|c|c|}
\hline \multicolumn{2}{|l|}{ Oxide Species } & $\begin{array}{c}\text { Spall } \\
\text { composition } \\
\text { (weight \%) }\end{array}$ & Element & $\begin{array}{c}\text { Spall composition } \\
\text { with Oxygen } \\
\text { removed } \\
(\text { weight } \%)\end{array}$ \\
\hline Aluminum Oxide & $\mathrm{Al}_{2} \mathrm{O}_{3}$ & $9.9 \%$ & Aluminium & $6.95 \%$ \\
\hline Arsenic (III) Oxide & $\mathrm{As}_{2} \mathrm{O}_{3}$ & $0.02 \%$ & Arsenic & $0.02 \%$ \\
\hline Chromium (III) Oxide & $\mathrm{Cr}_{2} \mathrm{O}_{3}$ & $4.93 \%$ & Chromium & $4.48 \%$ \\
\hline Cobalt (II) Oxide & $\mathrm{CoO}$ & $9.3 \%$ & Cobalt & $9.71 \%$ \\
\hline Copper Oxide & $\mathrm{CuO}$ & $0.02 \%$ & Copper & $0.02 \%$ \\
\hline Hafnium (IV) Oxide & $\mathrm{HfO}_{2}$ & $0.07 \%$ & Hafnium & $0.08 \%$ \\
\hline Iron (III) Oxide & $\mathrm{Fe}_{2} \mathrm{O}_{3}$ & $3.13 \%$ & Iron & $2.91 \%$ \\
\hline Manganese (II,III) Oxide & $\mathrm{Mn}_{3} \mathrm{O}_{4}$ & $0.01 \%$ & Manganese & $0.01 \%$ \\
\hline Molybdenum (VI) Oxide & $\mathrm{MoO}_{3}$ & $0.62 \%$ & Molybdenum & $0.55 \%$ \\
\hline Nickel Oxide & $\mathrm{NiO}$ & $61.84 \%$ & Nickel & $64.50 \%$ \\
\hline Potassium Oxide & $\mathrm{K}_{2} \mathrm{O}$ & $0.02 \%$ & Potassium & $0.02 \%$ \\
\hline Silicon Dioxide & $\mathrm{SiO}_{2}$ & $0.12 \%$ & Silicon & $0.07 \%$ \\
\hline Tantalum Oxide & $\mathrm{Ta}_{2} \mathrm{O}_{5}$ & $5.86 \%$ & Tantalum & $6.37 \%$ \\
\hline Terbium (III) Oxide & $\mathrm{Tb}_{2} \mathrm{O}_{3}$ & $0.01 \%$ & Terbium & $0.01 \%$ \\
\hline Thulium (III) Oxide & $\mathrm{Tm}_{2} \mathrm{O}_{3}$ & $0.01 \%$ & Thulium & $0.01 \%$ \\
\hline Titanium Dioxide & $\mathrm{TiO}_{2}$ & $0.43 \%$ & Titanium & $0.34 \%$ \\
\hline Tungsten (VI) Oxide & $\mathrm{WO}_{3}$ & $3.72 \%$ & Tungsten & $3.92 \%$ \\
\hline Yttrium Oxide & $\mathrm{Y}_{2} \mathrm{O}_{3}$ & $0.02 \%$ & Yttrium & $0.02 \%$ \\
\hline Zinc Oxide & $\mathrm{ZnO}$ & $0.01 \%$ & Zinc & $0.01 \%$ \\
\hline
\end{tabular}

Table 2 XRF analysis of LDSX-8 spall and conversion into 'unoxidised' spall composition (weight \%)

The first key observation was the presence of $\mathrm{Fe}_{2} \mathrm{O}_{3}$ in the spall; the alloy specifications for this element are very tight so the source cannot be the original casting, and these elements did not appear in the casting composition (Table 4), so the source must have been external. The source was traced back to oxides from the MA956 furnace architecture that must have fallen in to the crucible and contaminated the spall during the protracted exposure time required to 
completely oxidise the sample. To account for this the nominal composition of MA956 has been scaled to the Fe content observed in the spall, and subtracted from the composition to calculate a new 'uncontaminated' composition (Table 3).

\begin{tabular}{|c|c|c|c|}
\hline Element & $\begin{array}{l}\text { MA956 nominal } \\
\text { composition } \\
\text { (weight } \%)\end{array}$ & $\begin{array}{l}\text { MA956 scaled } \\
\text { to spall Fe } \\
\text { (weight\%) }\end{array}$ & $\begin{array}{l}\text { Spall composition with } \\
\text { Oxygen and MA956 } \\
\text { removed (weight\%) }\end{array}$ \\
\hline Aluminum & $4.75 \%$ & $0.14 \%$ & $7.08 \%$ \\
\hline Arsenic & - & - & $0.02 \%$ \\
\hline Chromium & $20 \%$ & $0.58 \%$ & $4.05 \%$ \\
\hline Cobalt & $0.30 \%$ & $0.01 \%$ & $10.07 \%$ \\
\hline Copper & $0.15 \%$ & $0.00 \%$ & $0.02 \%$ \\
\hline Hafnium & - & - & $0.08 \%$ \\
\hline Iron & $73.05 \%$ & $2.91 \%$ & $0.00 \%$ \\
\hline Manganese & $0.30 \%$ & $0.01 \%$ & $0.00 \%$ \\
\hline Molybdenum & - & - & $0.57 \%$ \\
\hline Nickel & $0.50 \%$ & $0.01 \%$ & $66.95 \%$ \\
\hline Potassium & - & - & $0.02 \%$ \\
\hline Silicon & - & - & $0.08 \%$ \\
\hline Tantalum & - & - & $6.61 \%$ \\
\hline Terbium & - & - & $0.01 \%$ \\
\hline Thulium & - & - & $0.01 \%$ \\
\hline Titanium & $0.45 \%$ & $0.01 \%$ & $0.34 \%$ \\
\hline Tungsten & - & - & $4.07 \%$ \\
\hline Yttrium & $0.50 \%$ & $0.01 \%$ & $0.01 \%$ \\
\hline Zinc & - & - & $0.01 \%$ \\
\hline
\end{tabular}

Table 3 Compositions of the MA956 and adjustment of the 'unoxidised' spall composition to remove it (weight \%)

Comparing this composition (Table 3) to the measured composition of the original casting (Table 4) reveals that the most significant differences are the absence of Re and $\mathrm{Ru}$ and the significant reduction in Mo. This simple comparison demonstrates conclusively that these elements have been lost by sublimation or volatilisation, although it cannot be conclusively 
proven that loss of these elements does not occur as part of a secondary break-down of the oxide species which are initially formed, however no significant presence of these elements are found in the oxide species found on the surface of these materials when examined in the SEM and XRD analyses.

\begin{tabular}{|c|c|c|}
\hline Element & $\begin{array}{c}\text { LDSX-8 casting } \\
\text { composition (weight \%) }\end{array}$ & $\begin{array}{c}\text { LDSX-8 casting } \\
\text { composition without } \\
\text { Re, Ru \& Mo (weight } \\
\% \text { ) }\end{array}$ \\
\hline Aluminum & $6.00 \%$ & $7.13 \%$ \\
\hline Chromium & $3.17 \%$ & $3.77 \%$ \\
\hline Cobalt & $8.20 \%$ & $9.74 \%$ \\
\hline Hafnium & $0.11 \%$ & $0.13 \%$ \\
\hline Molybdenum & $5.28 \%$ & - \\
\hline Nickel & $55.13 \%$ & $65.51 \%$ \\
\hline Rhenium & $6.35 \%$ & - \\
\hline Ruthenium & $4.63 \%$ & - \\
\hline Tantalum & $6.47 \%$ & $7.69 \%$ \\
\hline Titanium & $0.30 \%$ & $0.36 \%$ \\
\hline Tungsten & $4.77 \%$ & $5.67 \%$ \\
\hline
\end{tabular}

Table 4 Measured composition of the LDSX-8 casting and recalculation of the composition to account for complete $\mathrm{Re}, \mathrm{Ru}$ and Mo volatilisation (weight \%)

Table 4 also shows the measured composition of the original casting adjusted by removing the $\mathrm{Re}, \mathrm{Ru}$ and Mo from the composition. The similarity between this composition and that for the metal content in the spalled oxide (Table 3) is sufficiently close, given the uncertainty in the compositional measurement methods, such that it supports the hypothesis that the composition is that which is remnant after the Re, $\mathrm{Ru}$ and Mo have been lost.

The detrimental role of Mo in cyclic oxidation has also been shown in this work. However, the mechanism by which the presence Mo detrimentally affects the cyclic oxidation performance of these Ni-base superalloy materials has not been determined. There also is clear evidence that $\mathrm{Re}, \mathrm{Ru}$ and Mo has been lost through volatilisation/sublimation during 
cyclic oxidation of Ni-base superalloys at typical operating temperatures. This work therefore

\section{$\underline{\text { Acknowledgements }}$}

The authors gratefully acknowledge Rolls-Royce plc., the Engineering and Physical Sciences Research Council (EPSRC) for the provision of material and funding.

The authors would like to highlight the contributions from John Todd and Emma Tang from Ceram for the XRF and ICP-OES analyses and Feng Li from Cambridge University for the XRD analysis.

\section{$\underline{\text { References }}$}

1. Reed, R.C., The Superalloys: Fundamentals and Applications, Cambridge University Press, Cambridge, 2008 
2. Savitsky, E., V. Polyakova, N. Gorina, N. Roshan, Physical metallurgy of platinum metals. 1978, Moscow: Oxford: Mir Publishers, Distributed by Pergamon. 299-307.

3. Colton, R., The Chemistry of Rhenium and Technetium. 1965, London: Interscience. 33-52.

4. Yaws, C.L., Handbook of Vapor Pressure vol.4, Inorganic Compounds and Elements. 1995, Houston; London: Gulf. 243-247.

5. Kawagishi, K., H. Harada, A. Sato, A. Sato, and T. Kobayashi, The oxidation properties of fourth generation single-crystal nickel-based superalloys. JOM, 2006. 58(1): p. 43.

6. Kawagishi, K.H., A. Sato, T. Kobayashi, and H. Harada, Effect of alloying elements on the oxidation behavior of 4 th generation Ni-Base single-crystal superalloys. JOM, 2004. 56(11): p. 275.

7. Feng, Q., B. Tryon, L.J. Carroll, and T.M. Pollock, Cyclic Oxidation of Rucontaining Single Crystal Superalloys at $1100 \mathrm{oC}$. Materials Science and Engineering A, 2007. 458(1-2): p. 184.

8. Bellina, P.J., A. Catanoiu, F.M. Morales, and M. Ruhle, Formation of Discontinuous A12O3 Layers During High-Temperature Oxidation of RuAl Alloys. Journal of Materials Research, 2006. 21(1): p. 276-286.

9. Tryon, B., Feng, Q., Wellman, R.G., Murphy, K.S., Yang, J., Levi, C.G., Nicholls, J.R., Pollock, T.M. Multilayered Ruthenium-Modified Bond Coats for Thermal Barrier Coatings. Metallurgical and Materials Transactions A, 2006. 37(11) p. $3347-3358$

10. Moniruzzaman, M., M. Maeda, Y. Murata, and M. Morinaga, Degradation of High-Temperature Oxidation Resistance for Ni-based Alloys by Re Addition and the Optimization of Re/Al Content. ISIJ International, 2003. 43(3): p. 386.

11. Moniruzzaman, M., Y. Murata, M. Morinaga, R. Hashizume, A. Yoshinari, and Y. Fukui, Alloy Design of Ni-based Single Crystal Superalloys for the Combination of Strength and Surface Stability at Elevated Temperatures. ISIJ International, 2003. 43(8): p. 1244-1252.

12. Murata, Y., M. Moniruzzaman, M. Morinaga, R. Hashizume, and A. Yoshinari. Double Bladed Effect of Re on High-Temperature Oxidation and Hot-Corrosion of Nickel-based Superalloys in THERMEC'2003. ed. T. Candra, J.M. Torralba, and T. Sakai. Madrid, Spain: Trans Tech Publications Ltd. 2003. p. 4561. 
13. Younes, C.M., G.C. Allen, and J.A. Nicholson, High Temperature Oxidation Behaviour of Single Crystal Superalloys RR3000 and CMSX-4. Corrosion Engineering, Science and Technology, 2007. 42(1): p. 80.

14. Speiser, R. and G.R. St. Pierre, Fundamentals of Refractory Metal-Gaseous Environmental Interaction, in The Science and Technology of Tungsten, Tantalum, Molybdenum, Niobium and Their Alloys. 1964, Pergamon Press: NY, US. p. 289-330.

15. Gonzalez Carrasco, J.L., P. Adeva, and M. Aballe, The role of microstructure on oxidation of Ni-Cr-Al base alloys at 1023 and $1123 \mathrm{~K}$ in air. Oxidation of Metals, 1990. 33(1-2): p. 18.

16. Hashizume, R., A. Yoshinari, T. Kiyono, Y. Murata, and M. Morinaga. Development of Ni-Based Single Crystal Superalloys for Power-Generation Gas Turbines in Superalloys 2004. ed. Warrendale, PA, USA: TMS. 2004. p. 53-62.

17. Goebel, J.A., F.S. Pettit, and G.W. Goward, Mechanisms for the hot corrosion of nickel-base alloys. Metallurgical Transactions, 1973. 4(1): p. 261-278.

18. Hobbs, R., Brewster, G., Rae, C., Tin, S., Proceed. Intern. Sympo. Superalloys., Champion, USA, Reed R.C., Green K.A., Caron P., Gabb T.P., Fahrmann, M.G., Huron, E.S. Woodard S.A. Eds., (TMS, 2008) pp. 171-180

19. Kamruddin, P. Ajikumar, K. Dash, S. Tyagi, A. Raj, B. Thermogravimetryevolved gas analysis-mass spectrometry system for materials research. Bulletin of Materials Science. 2003. 26(44). p. 449-460. 


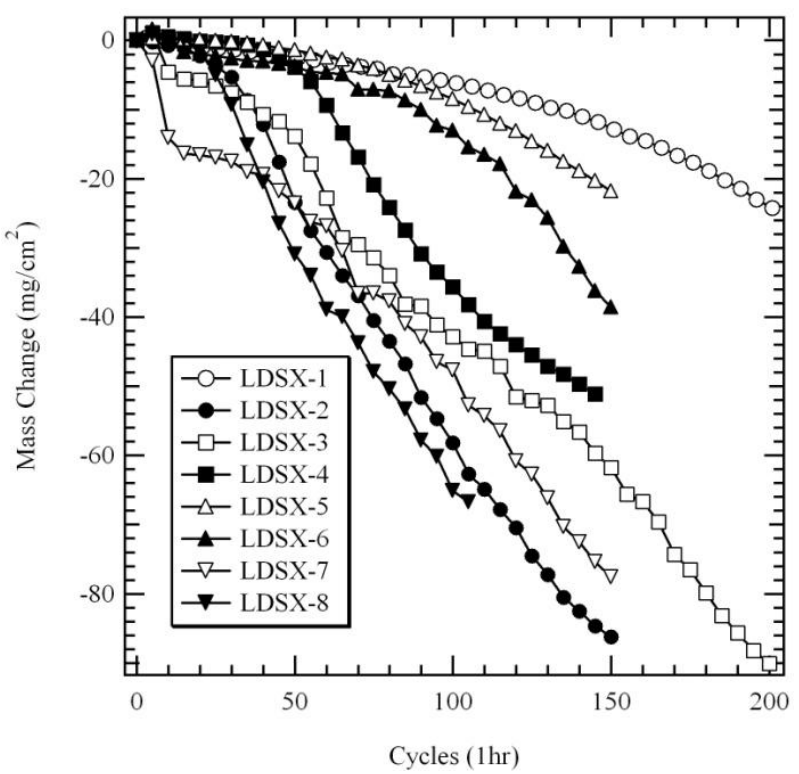

Figure $11100^{\circ} \mathrm{C}$ cyclic oxidation resistance of the bare LDSX alloys.

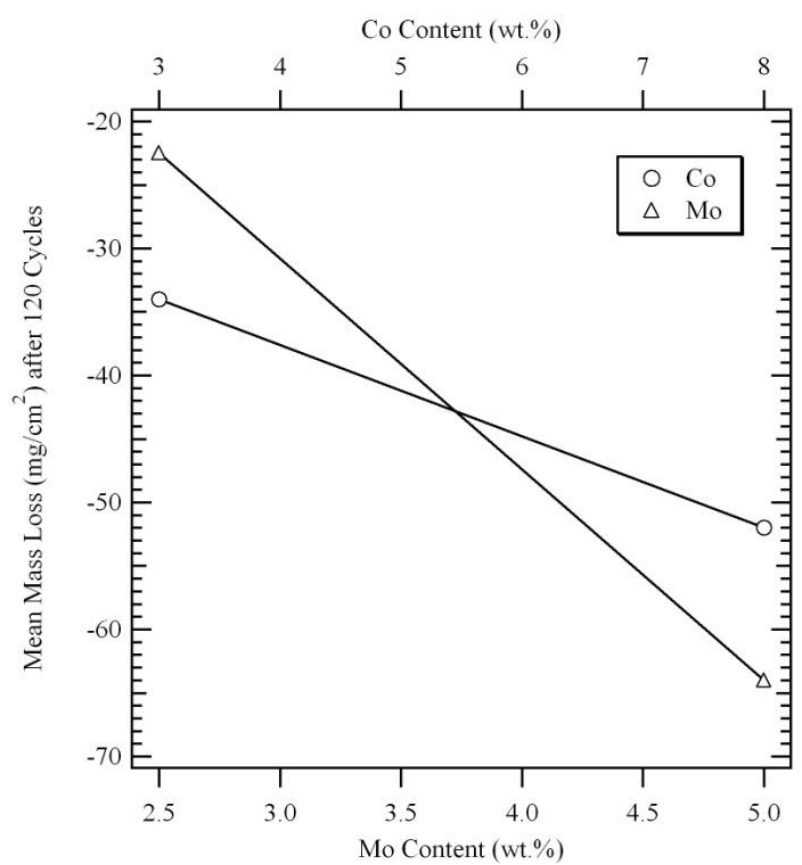

Figure 2 Output from the DoE showing the detrimental effects of increasing Co and Mo contents on the $1100^{\circ} \mathrm{C}$ cyclic oxidation resistance of the bare LDSX alloys. 


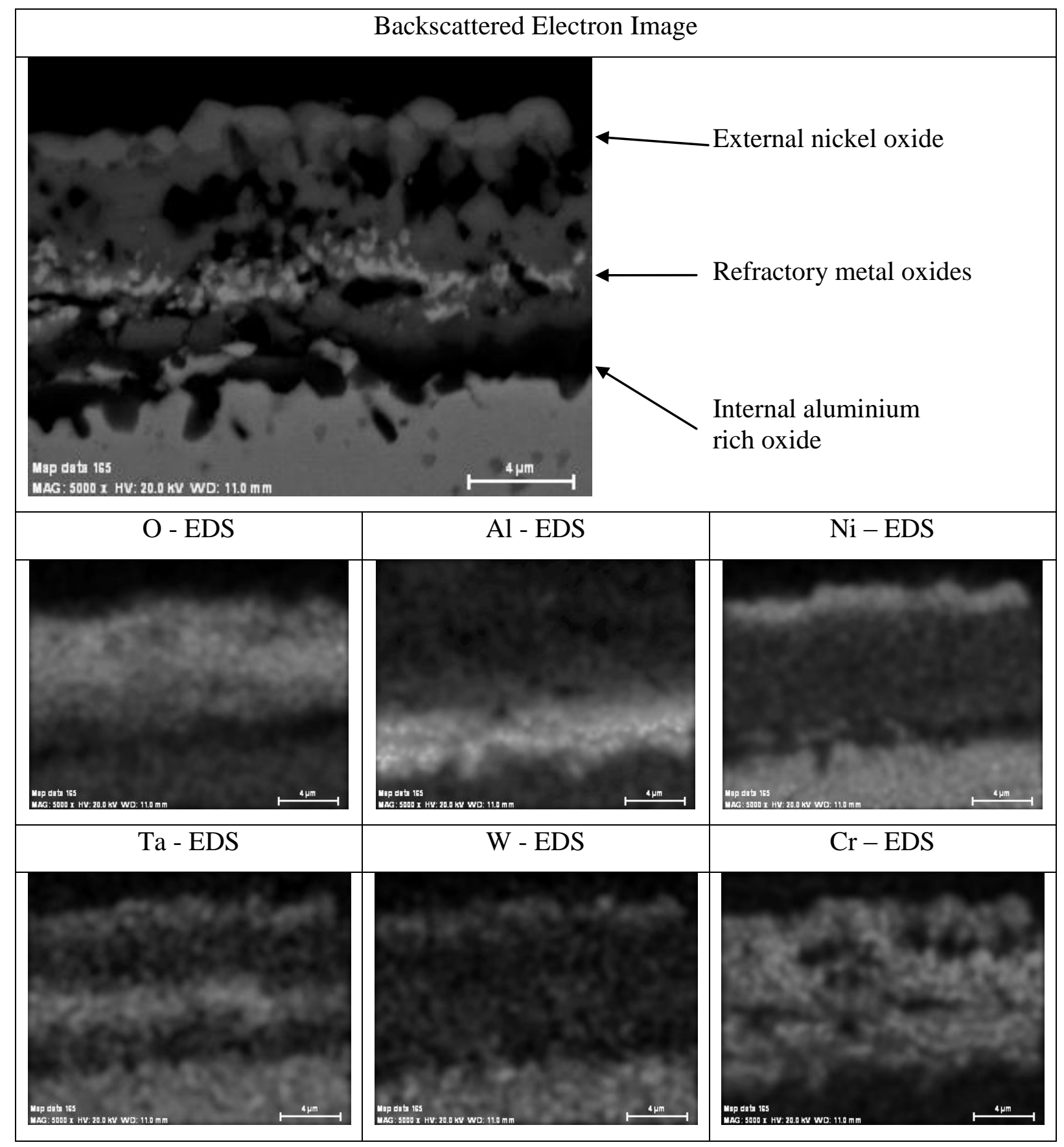

Figure 3 Backscattered electron image and EDS compositional maps of typical bare LDSX-1 $1100^{\circ} \mathrm{C}$ cyclic oxidation microstructure after $200 \mathrm{hs}$ 


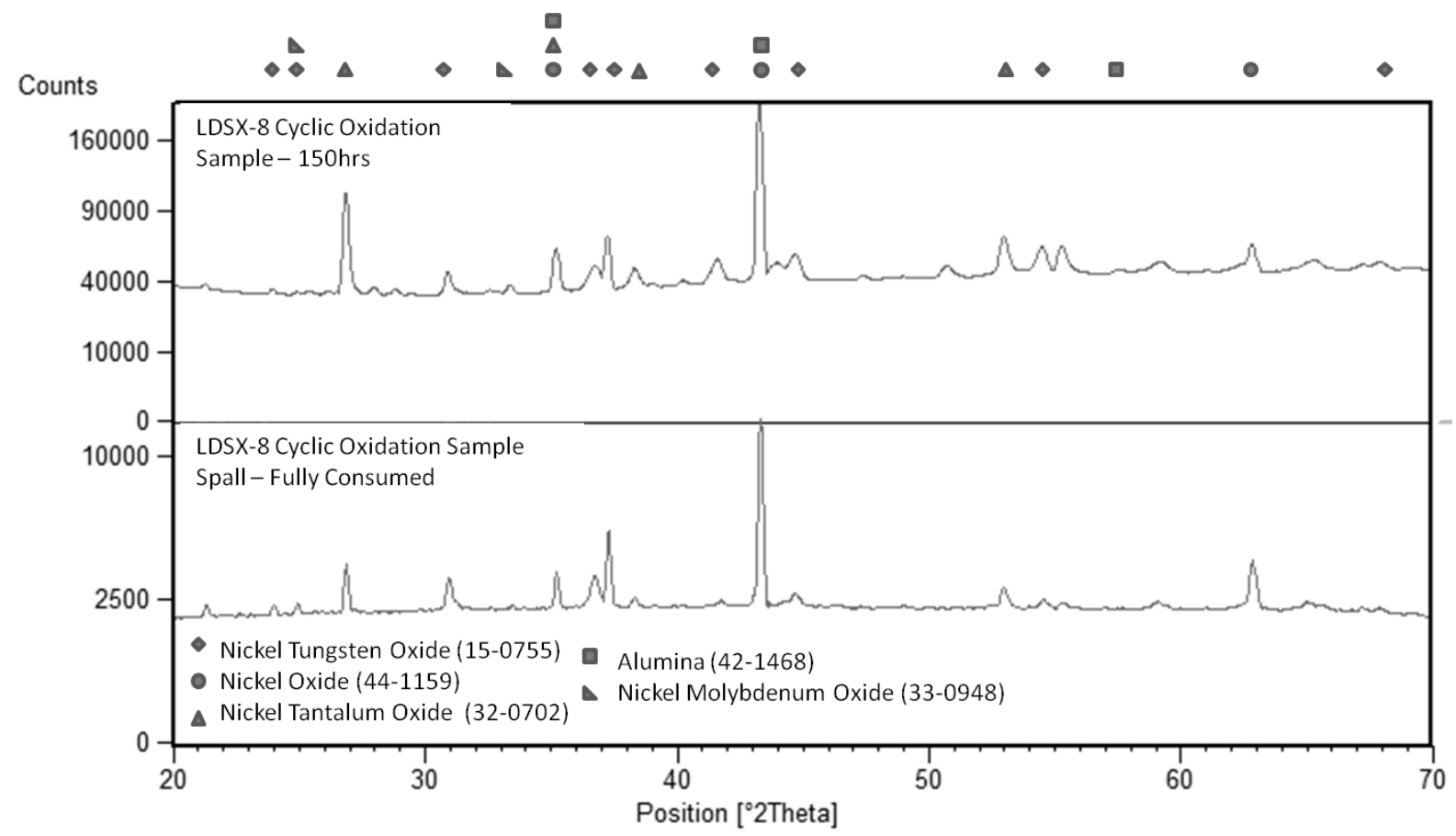

Figure 4 XRD analyses of LDSX 8 samples: TOP - Cyclic oxidation sample - 150 hs; BOTTOM - Fully consumed 

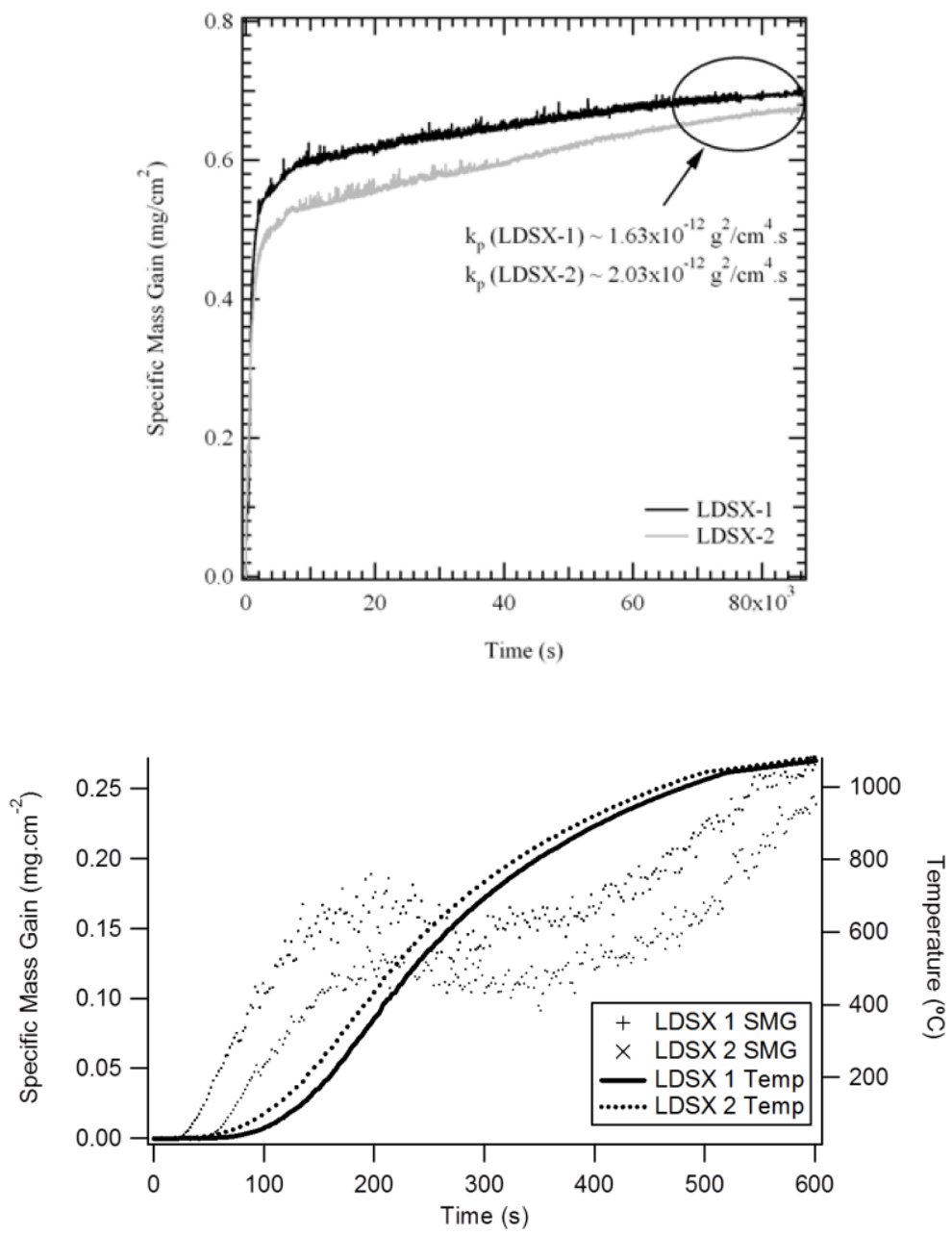

Figure 5 TGA trace of LDSX-1 and LDSX-2 at $1100^{\circ} \mathrm{C}$ : TOP - Complete $24 \mathrm{~h}$ trace; BOTTOM - Initial transient behaviour 